\title{
Preface: Magmatic and Tectonic Process, Seabed Resource from the mid-ocean ridge to continental margin
}

\author{
Weiwei Ding ${ }^{1,2} \cdot$ Jiabiao $^{\mathrm{Li}^{1,2}} \cdot$ Minghui Zhao $^{3}$
}

Published online: 31 March 2017

(C) The Author(s) 2017. This article is published with open access at Springerlink.com

In the end of 2015 the 3rd InterRidge Theoretical Institute was hold in Hangzhou, China. Scientists from more than ten countries have presented their works about recent studies on oceanic lithospheric structure, seafloor morphology, deformation features (detachments, oceanic core complex, etc), complex ridge-transform evolution and mantle exhumation, and hydrothermal process and its interaction with magmatic and tectonics process. The idea for present volume occurred to Professor Jiabiao Li, the chairman of the InterRidge, Dr. Weiwei Ding and Dr Minghui Zhao. They have been working together on the active tectonics and interplate deformation from the mid-ocean ridge to continental margin since 2000. This special issue on the Magmatic and Tectonics Process, Seabed Resource from the mid-ocean ridge to the continental margin has amassed 13 papers dealing with Indian Ocean, West Pacific Ocean and South China Sea region and includes two papers focusing on the continental shelf of the East China Sea.

Five works in this special issue present new results about the lithospheric structure, mantle exhumation and related hydrothermal process of the mid-ocean ridge based on recent-acquired geophysical, geological and geochemical data. Tao et al. (2017a, this special issue) discussed the turbidity, oxidation-reduction potential, and temperature

Weiwei Ding

wwding@sio.org.cn

1 Key Laboratory of Submarine Geoscience, State Oceanic Administration, Hangzhou 310012, China

2 The Second Institute of Oceanography, State Oceanic Administration, Baochubei Road 36, Hangzhou 310012, China

3 Key Laboratory of the Marginal Sea Geology, South China Sea Institute of Oceanography, Chinese Academy of Sciences, Guangzhou 510301, China anomalies of hydrothermal plumes from the Zouyu- 1 and Zouyu-2 hydrothermal fields on the southern Mid-Atlantic Ridge, and used them to evaluate their effects in locating active vent sites and mapping seafloor sulfide deposits. Tao et al. (2017b, this special issue) also analyzed the spatial distribution of shallow structures in the Longqi hydrothermal field, Southwest Indian Ridge, with recently acquired near-bottom magnetic data, and studied the demagnetization mechanism of the hydrothermal alteration zone. Luo et al. (2017, this special issue) relocated two earthquake events in the Southwest Indian Ridge with combined analysis on wide-angle seismic data recorded by ocean bottom seismometers and onland seismic stations. Ruan et al. (2017, this special issue) used passive seismic data recorded by ocean bottom seismometer to invert the crustal structure and mantle transition zone thickness in the Southwest Indian Ridge. The velocity structure shows that the 410 discontinuity is depressed by $\sim 15 \mathrm{~km}$, the 660 discontinuity is elevated by $\sim 18 \mathrm{~km}$, and a positive thermal anomaly between 182 and $237 \mathrm{~K}$ is inferred. Chen et al. (2017, this special issue) revealed the mantle source heterogeneity and magmatic evolution at Carlsberg Ridge with constraints from elemental and isotopic $(\mathrm{Sr}, \mathrm{Nd}, \mathrm{Pb})$ data. Their results proved the long-term preservation of continental material in the oceanic mantle.

There are two contributions focus on the formation history and occurrence about sulfide deposits. Suo et al. (2017, this special issue) analyzed the tectonic and magmatic setting favor for the occurrence hydrothermal systems along the Southwest Indian Ridge and proposed the potential hydrothermal systems unexplored in this region. Yang et al. (2017, this special issue) carried out a complementary geochronological study on the growth history of hydrothermal sulfides in the ultraslow-spreading Southwest Indian Ridge 
with ${ }^{230} \mathrm{Th} /{ }^{238} \mathrm{U}$ dating method, and divided the hydrothermal activity into four episodes.

Basin dynamics of marginal basins is another major topic of this special issue, especially the South China Sea, the Okinawa Trough and the Philippine Sea. Yu et al. (2017, this special issue) derived a detailed P-wave velocity model of the Southwest Sub-basin in the South China Sea, and conducted a detailed study of the crustal structures of the abyssal basin and northern margin. An asymmetric extension pattern was discovered which may related to large-scale detachments. Another try considering the deep structure and role of rifting in this area was carried out by Lu et al. (2017, this special issue). With one reflection and refraction profile cross the whole oceanic basin, they found extensive deformation of the brittle crust during the asymmetric continental rifting, and further suggested the continental margin of the Southwest Sub-basin had experienced three rifting stages. With wide-angle seismic data and optimum P-wave model, Wei et al. (2017, this special issue) showed an S-wave velocity structure across the Northwestern Sub-basin of the South China Sea. They argued the northwestern continental margin of this subbasin is a magma-poor type, and the Macclesfield Bank (Zhongsha Islands) was connected with the Reed Bank before the continental break-up. Liu et al. (2017, this special issue) determined the strikes and spatial distributions of the transform faults in the Okinawa Trough on the basis of seismic, gravity and region geological data. They argued that these transform faults were inherited from pre-existing oblique transtensional faults at the offsets between rifting segments. Wang et al. (2017, this special issue) identified basement-involved faults and linear structures based on the high-order derivative analysis on gravity anomalies in the West Philippine Basin.

Three papers in this special issue consider the geomorphology features and their tectono-sedimentary significance. With new multi-beam sonar data, some special geological units, such as the giant volcanos in the Pacific, or the regressive sand ridges on the continental shelf of the East China Sea, are well illustrated, and their tectono-sedimentary significances were detailed discussed. Zhang et al. (2017, this special issue) studied the bathymetric features and structures of the Shatsky Rise which lies in the ridge-ridge-ridge triple junction in West Pacific, and confirmed that the Tamu Massif is an immense central volcano with thin sedimentary cover. Numerous cones were also discovered implying later-stage volcanism. Wu et al. (2017a, this special issue) identified linear sand ridges on the continental shelf of the East China Sea and analyzed them in details to reveal the paleo-topography evolution history during the last $300 \mathrm{ka}$. A new method to identify the foot of continental slope was introduced by $\mathrm{Wu}$ et al. (2017b, this special issue) based on an integrated morphological profile analysis. The slope foot is an essential element for the delimitation of outer continental shelf beyond 200 nautical miles requested by the Commission on the Limits of the Continental Shelf (CLCS).

Acknowledgements We thank all the contributors to this special issue for their valuable participation and the referees who devoted their time and efforts to provide insightful reviews. This special issue is financially supported by the National Programme on Global Chang and Air-Sea interaction, SOA (No. GASI-GEOGE), and the Dream Project of MOST of China (No. 2016YFC0600402).

Open Access This article is distributed under the terms of the Creative Commons Attribution 4.0 International License (http:// creativecommons.org/licenses/by/4.0/), which permits unrestricted use, distribution, and reproduction in any medium, provided you give appropriate credit to the original author(s) and the source, provide a link to the Creative Commons license, and indicate if changes were made. 